\title{
Crítica à formação profissional em Serviço Social no ensino a distância
}

\author{
Criticism to the professional qualification in Social Work \\ in distance learning
}

\section{Antonio Israel Carlos da Silva*}

\begin{abstract}
Resumo - Este artigo analisa as características da metodologia de ensino e o formato da organização curricular da proposta político-pedagógica de formação profissional em Serviço Social. Para tanto, o foco é a modalidade ensino a distância, em uma instituição de ensino superior selecionada para o estudo. Situamos, incialmente, a dinâmica de expansão dos cursos de Serviço Social através do EaD no Brasil e no Ceará. O percurso metodológico desenvolvido consiste em revisão de literatura e pesquisa documental. Assim, apreendemos que o processo formativo na modalidade estudada desenvolve um ensino estrito, mediado por Tecnologias da Informação e Comunicação (TICs) que, por sua vez, virtualizam a dinâmica pedagógica, desconsiderando o processo de ensino/aprendizagem calcado na relação entre ensino, pesquisa e extensão; além disso, apresenta ausência de contato mais profundo entre professores e estudantes, esboçando uma proposta político-pedagógica cujo formato de organização curricular tende a reproduzir um caráter tecnicista, pragmático e residual na formação profissional em Serviço Social.
\end{abstract}

Palavras-chave: ensino superior; Serviço Social; formação profissional.

\begin{abstract}
This article analyzes the characteristics of teaching methodology and the format of curricular organization in the political-pedagogical proposal for professional qualification in Social Work. To that effect, it is centered on distance learning in selected higher education institutions. Initially we focused on the dynamic of expansion of social work courses through the distance learning in Brazil and the Ceará state. The methodological approach we developed consisted of a literature review and documental research. Therefore, we apprehended that the process of the professional qualification studied is a narrow method, mediated by information and communication technologies (ICTs), which virtualizes the pedagogical dynamics, neglecting the teaching/learning process based on the relation between education, research and extension. Furthermore, it forgoes deeper contact between teachers and students, and draws a politicalpedagogical proposal of curricular organization whose format tends to reiterate a character of technicality, pragmatism and deficiency in the professional qualification in Social Work.

Keywords: higher education; Social Work; professional qualification.
\end{abstract}

\footnotetext{
* Mestrando em Serviço Social pela Universidade Federal de Pernambuco (UFPE). Correspondência: Avenida dos Economistas, s/n-Cidade Universitária, Recife/PE. CEP: 50670- 901. Email: <israelsscarlos@gmail.com>
} 


\section{Introdução}

A formação profissional em Serviço Social no Brasil tem sido tensionada pelas transformações societárias e pelas configurações na política de ensino superior, cujas reverberações, em particular a partir dos anos 2000, explicitaram o crescimento da oferta de cursos de Serviço Social em instituições privadas de ensino superior, nas modalidades presencial e a distância. No artigo que ora apresentamos, analisamos as características da metodologia de ensino e o formato da organização curricular da proposta político-pedagógica de formação profissional em Serviço Social, na modalidade ensino a distância (EaD), em uma Instituição de Ensino Superior (IES), a saber, a Universidade do Norte do Paraná (Unopar). Desse modo, situamos, incialmente, a dinâmica de expansão dos cursos de Serviço Social no Brasil e, mais especificamente, no Ceará.

Com o escopo de alcançar o objetivo do artigo, apropriamo-nos do método crítico-dialético para análise das questões apontadas. Este método caracteriza-se por conceber a realidade em sua contraditoriedade, totalidade e concretude, buscando desvelar a essência dos fenômenos (MARX, 2008). Quanto à metodologia, utilizamos revisão de literatura, a partir do aporte teórico sobre o ensino superior e a formação profissional em Serviço Social no Brasil. Foi realizada pesquisa documental no site eletrônico do Ministério da Educação, para coleta de dados sobre legislação e planejamento educacional, além de obtenção de estatísticas da expansão dos cursos de Serviço Social EaD no Brasil e no Ceará. Particularmente, analisamos o documento denominado Guia de Percurso do Curso de Serviço Social, que corresponde à proposta político-pedagógica de formação profissional EaD da Unopar, tendo em vista problematizar as características da metodologia de ensino apresentada e o formato da organização curricular. A coleta da proposta de formação da Unopar ocorreu através de pesquisa exploratória no site eletrônico da referida instituição'.

Como assinala Mészáros (2008), o impacto da lógica do capital sobre a educação tem intercorrido de modo agravante. A educação institucionalizada, sob a égide do capitalismo, tem buscado cumprir um papel não somente de fornecimento de conhecimento e formação de trabalhadores necessários à máquina produtiva capitalista, como também se imbui da função de gerar e garantir um quadro de valores que legitimem a ideologia dominante. Deste modo, o autor citado explicita que a educação tem se subordinado aos imperativos do capital, sendo desconfigurada da condição de um direito para se tornar mercadoria.

\footnotetext{
${ }^{1}$ Escolhemos a Unopar pelo fato de que esta IES é líder na oferta nacional de vagas anuais para o curso de Serviço Social, com 21.150 vagas; além disso, por possuir grande concentração de polos no Ceará. Declaramos que os dados explicitados sobre esta IES encontram-se disponibilizados em seu site eletrônico. Não analisamos nenhum material de caráter sigiloso e, deste modo, não foi necessário utilizar nome fictício para caracterizá-la.
} 
Neste quadro, visualizamos, a partir dos anos 2000, o crescimento exacerbado da oferta de cursos de Serviço Social em instituições de ensino superior privadas, nas modalidades de ensino presencial e a distância. $\mathrm{O}$ modelo de educação-mercadoria, em que prevalece a privatização em grau elevado, colabora para a existência de formações aligeiradas e fragmentadas (RODRIGUES, 2007), que priorizam o quantitativo em detrimento da qualidade dos processos pedagógicos envolvidos. Podemos argumentar que este processo não é, obviamente, exclusivo do curso de Serviço Social; no entanto, nossa atenção no artigo em exposição debruça-se sobre as particularidades da formação profissional neste curso específico.

Através da leitura de Pereira (2014) apreendemos que o ensino a distância, como mediação pedagógica no ensino superior, teve seu fomento na Lei n. 9.394/96, conhecida como Lei de Diretrizes e Bases da Educação Nacional (LDB/96) (BRASIL, 1996). Além disso, foi regulamentado no artigo 80 da referida lei, passando a ser amplamente utilizado no Brasil no processo de formação de professores e, em seguida, abarcando os cursos de bacharelado, a exemplo do curso de Serviço Social. A autora em questão considera que o EaD "trata-se de uma modalidade de ensino que possibilita ao setor privado uma rápida e lucrativa expansão de matrículas, constituindose como importante alternativa a um mercado cujo público consumidor apresenta históricas limitações financeiras" (PEREIRA, 2014, p. 18).

De acordo com Pereira (2014), o Plano Nacional de Educação (PNE - 2001-2011) apontava a necessidade de ampliar em 30\% o acesso da população jovem, entre 18 e 24 anos, ao ensino superior, identificando o atraso educacional no qual se encontrava o Brasil frente aos demais países latino-americanos. Atualmente, como frisa a autora, menos de $12 \%$ da população nessa faixa etária, no Brasil, tem acesso ao ensino superior, ficando em situação desfavorável diante de países como Chile $(20,6 \%)$, Venezuela (26\%) e Bolívia (20,6\%). Neste aspecto, introduzir o EaD iria corresponder à necessidade de massiva ampliação das vagas no ensino superior. Destarte, o processo de expansão do ensino a distância corresponde a um movimento que tende a descaracterizar o papel da universidade na sociedade, enquanto produtora de conhecimento, baseado na relação indissociável entre ensino, pesquisa e extensão, haja vista que o modelo pedagógico adotado pelo EaD não privilegia a tríade fundamental do ensino superior.

As mudanças operadas no ensino superior brasileiro, nos primeiros anos do século XXI, estão relacionadas ao conjunto de ações e proposições realizadas no governo Luiz Inácio Lula da Silva (2003-2010), no sentido de aprofundamento da ideologia neoliberal na educação. Isto ocorreu através de uma nova processualidade no desmantelamento dos serviços públicos e por intermédio da implementação de medidas necessárias para que a educação, como um direito, fosse convertida em mercadoria. Partindo desta indicação, encontramos em Cislaghi (2012) a afirmação de que a disputa 


\section{ApVistg all paUtg}

\} CRÍTICA À FORMAÇÃO PROFISSIONAL - SILVA, A. I. C. \}

DOI: 10.12957/REP.2016.25389

pelo fundo público no setor educacional, no contexto do Governo Lula, fomentou a ampliação do ensino superior privado.

Cislaghi (2012) destaca o Programa Universidade Para Todos (ProUni - Lei n. 11.096, de 13 de janeiro de 2005) como instrumento utilizado para distribuir bolsas integrais e parciais em IES privadas aos estudantes de baixa renda. Em troca, cabe ao governo a garantia de isenções fiscais aos grupos educacionais que aderirem. A renúncia fiscal do governo chega a 126,05 milhões de reais; além disso, grande parte das IES que aderiram ao ProUni estavam com dívidas fiscais. Portanto, o ProUni pode ser considerado um grande negócio para os empresários da educação.

Outra problemática incide sobre o Programa de Apoio a Planos de Reestruturação e Expansão das Universidades Federais (Reuni), cujo principal objetivo é a ampliação do acesso e da permanência na educação superior pública. Entre suas medidas, está o aligeiramento dos cursos de graduação, tornando-os mais breves. Tal projeto também busca o aumento da proporção professor/aluno, que era de 12 estudantes por professor e passa a ser de 18 estudantes para cada docente (BRASIL, 2013).

A universidade pública, gratuita, laica e de qualidade vem sendo tensionada pela iniciativa privada, promovida pela ação do Estado. Este, por sua vez, permite que o processo de mercantilização da educação se efetive com maior intensidade. Assim, a universidade que defendemos, "[...] que cultiva razão crítica e o compromisso com valores universais, coerente com sua função pública [...]" (IAMAMOTO, 2011, p. 432), é negligenciada em prol da política educacional de cunho neoliberal, que imprime uma lógica mercantil e empresarial à universidade brasileira.

O cenário de configurações da política de ensino superior brasileira, em que se amplia a precarização da educação através da mercantilização do ensino e das medidas de redução de recursos para a educação pública, tem atingido profundamente a formação profissional em Serviço Social. Processo que tem se desenvolvido através da ação da hegemonia empresarial, em meio à tônica de crescimento do número de cursos no circuito mercantil do ensino, colocando o curso de Serviço Social como um novo "nicho de mercado". De modo específico, a partir de 2006, o Serviço Social inseriu-se na modalidade ensino a distância, explicitando o aprofundamento da precarização e mercantilização do processo formativo. Trata-se, portanto, de um processo de tensionamento posto ao Serviço Social, alvo central de nosso debate nas páginas que se seguem.

\section{O EaD no ensino superior brasileiro: expressão de um processo de configuração da política educacional}

O ensino superior, na América Latina e no Brasil, sofreu fortes rebatimentos da perspectiva educacional proposta pelo Banco Mundial 


\section{ReVistg ell pautg}

\} CRÍTICA À FORMAÇÃO PROFISSIONAL - SILVA, A. I. C. \}

DOI: 10.12957/REP.2016.25389

para os países da periferia do capitalismo. O receituário evidenciado por este organismo internacional tem explicitado concepções ideológicas sobre as estratégias de expansão do ensino superior. As sínteses das medidas do Banco Mundial para o ensino superior são relevadas nos seguintes eixos: diferenciação institucional; diversificação das fontes de financiamento do ensino público; redefinição da função do Estado no ensino superior; e alcance dos objetivos de qualidade e equidade (com aporte nas exigências do mercado de trabalho) (BANCO MUNDIAL, 1994). As propostas correspondem à implementação de um processo de configuração do ensino superior, que no Brasil se materializou de modo intenso nos governos $\mathrm{FHC}$ (Fernando Henrique Cardoso), Luiz Inácio Lula da Silva e Dilma Rousseff.

Lima (2007) destaca que as políticas dos organismos internacionais estão inseridas no binômio pobreza-segurança, com a função de escamotear as relações de dependência entre as nações. O que se processa no movimento do real é a adequação estrutural elaborada pelos países centrais para a manutenção de relações imperialistas. A política desempenhada por essas organizações entoam a perspectiva de alívio da pobreza; destarte, o invólucro do enfrentamento não significa, de fato, a superação desta. Trata-se de uma instrumentalização do alívio da pobreza, que objetiva garantir legitimidade e segurança para a reprodução do capital. Outo aspecto das políticas dos organismos é a reafirmação da promessa inclusiva da educação: "[...] o projeto hegemônico reivindica a inevitabilidade da realização da reforma educacional sob a aparência de uma política inclusiva dos segmentos pauperizados da população" (LIMA, 2007, p. 52).

No âmbito específico das configurações arroladas na política brasileira de ensino superior, diante do contexto mais amplo de financeirização e mundialização do capital (CHESNAIS, 2002), transformações no mundo do trabalho, acumulação flexível (HARVEY, 1993) e contrarreforma do Estado, particularmente nos anos 2000, a tônica expansionista passou a utilizar a modalidade de ensino a distância como um dos instrumentos de ampliação de vagas. Este processo foi engendrado com a regulamentação do artigo 80 da LDB de 1996, que oficializa o desenvolvimento de uma política nacional de ensino superior a distância no Brasil, com novas formas e conteúdos, justificada pela articulação entre as regras dos organismos internacionais e o Estado, à época sob o comando do Governo FHC.

Diante do discurso de mudança urgente da educação, as medidas requisitadas pela nova ordem hegemônica do capital, nos marcos do ideário de "globalização econômica" e de "sociedade da informação", com aporte da internet, como uma das principais Tecnologias da Informação e Comunicação (TICs), o EaD passou a ser utilizado como estratégia para atualização tecnológica e formação de professores da educação básica. Além disso, também pela garantia do processo denominado por Lima (2011) de "certificação em larga escala" (a partir da introdução de cursos de bacha- 


\section{ApVistg all paUtg}

\} CRÍTICA À FORMAÇÃO PROFISSIONAL - SILVA, A. I. C. \}

DOI: 10.12957/REP.2016.25389

relado), nos marcos da diversificação dos cursos, das IES e das fontes de financiamento para ampliação da oferta.

Sobre as TICs, cabe ressaltar que autores como Castells (2003) e Drucker (1993) dimensionam como um dos instrumentos centrais na formação do homem contemporâneo, afirmando que, a partir desses mecanismos, a informação tende a ser difundida de modo rápido e massivo. Particularmente, os autores chegam a afirmar que a centralidade do trabalho tende a ser substituída pela informação, e discutem a ideia de "sociedade do conhecimento" e "sociedade da informação", articulada à ideia de "sociedade em rede". Ou seja, postulam uma afirmação equivocada quanto ao papel do "conhecimento", confundindo-o com informação na sociedade, haja que vista que o trabalho não deixa de assumir centralidade. O que ocorre, de fato, é a intensificação da exploração e precarização do trabalho. Neste sentido, a perspectiva de formação educacional virtual assenta-se na concepção de sociedade informacional, o que, por sua vez, descaracteriza o sentido crítico, propositivo, dialético e reflexivo da educação, negando-a como mecanismo contributivo do processo de emancipação política e humana, incorporando-a à dinâmica operacional, segmenta e alienada do mercado de trabalho.

A expansão do ensino superior brasileiro nas primeiras décadas do século XXI tem sido desenvolvida por um duplo dinamismo, explicitado no processo de expansão das matrículas no ensino público (através do Reuni, das políticas de cotas e de ações afirmativas). Sua dinâmica expansionista, contraditoriamente, evidencia uma maior preocupação com as dimensões quantitativas, em detrimento da necessária qualidade no desenvolvimento político-pedagógico do ensino. Outra faceta deste fenômeno é apresentada no movimento do real como expressão da intensificação dos mecanismos de mercantilização da educação. Neste aspecto, há inversão da concepção de educação como direito social, submetendo-a, no bojo do cenário neoliberal, a um instrumento mercadológico fortalecido pelo Estado (através da política de isenção fiscal) e pelos empresários; estes últimos acumulam capital com mediação da "venda" de serviços educacionais.

De acordo com dados do Inep, em 2013, havia 2.391 IES no Brasil, das quais 12,6\% (301) eram públicas e 87,4\% (2.090) eram privadas. Quanto à organização acadêmica das IES, os números apontam que: apenas $8,1 \%$ (195) eram universidades; 5,8\% (140), centros universitários; 84,3\%, faculdades; e 1,7\% (40) dizia respeito aos Institutos Federais de Educação, Ciência e Tecnologia. Quanto ao número de matrículas, os dados de 2013 evidenciam que, do total de 7.305.977 de estudantes matriculados no ensino superior, $26,5 \%$ estavam situados no ensino público e $73,5 \%$ na inciativa privada (INEP, 2013).

Os números acima explicitam que, de fato, a política de expansão do ensino superior brasileiro tem seguido o conjunto de determinações do Banco Mundial. As políticas promovidas pelos organismos internacionais 


\section{heVistg enl pautg}

\} CRÍTICA À FORMAÇÃO PROFISSIONAL - SILVA, A. I. C. \}

DOI: 10.12957/REP.2016.25389

nos anos 1990 (Banco Mundial, Unesco, Organização Mundial do Comércio - OMC, Fundo Monetário Internacional - FMI) buscaram orientar um conjunto de reformas econômicas e políticas nos países da periferia do capitalismo. No bojo das reformas neoliberais estão inseridas reformas educacionais de monta, que vão atravessar o final do século XX e inserir-se com vigor nas primeiras décadas do século XXI.

É perceptível o aumento das IES privadas em relação à quantidade de públicas, processo desenvolvido por intermédio da diferenciação institucional das IES, pois não houve grande crescimento de universidades (estas que são pautadas pelo tripé ensino, pesquisa e extensão). A lógica, portanto, é dimensionar a expansão de instituições voltadas somente para o ensino de graduação, limitando as possibilidades de ampliação das vivências acadêmicas e políticas. Nesse cenário, o EaD tornou-se um dos mecanismos mais utilizados na expansão, interiorização e regionalização da educação.

\section{Tabela 1}

\section{O processo de expansão das matrículas no EaD no ensino superior entre 2002-2012, conforme natureza jurídica}

$\begin{array}{llll}\text { Ano } & \text { Total } & \text { Público } & \text { Privado } \\ \mathbf{2 0 0 2} & 40.714 & 34.322 & 6.392 \\ \mathbf{2 0 0 6} & 207.206 & 42.061 & 165.145 \\ \mathbf{2 0 1 0} & 930.179 & 182.602 & 748.577 \\ \mathbf{2 0 1 2} & 1.113 .850 & 181.624 & 932.226\end{array}$

Fonte: Elaboração do autor com base em Inep (2013) e Cruz (2015)

A tabela acima evidencia a dinâmica de expansão do EaD no ensino superior brasileiro, entre os anos de 2002 e 2012. Os dados de 2002 mostram que o próprio Estado atuou como agente expansionista do EaD, diversificando as modalidades de ensino, conforme as recomendações do Banco Mundial. A partir de 2006, os números passam a se inverter, com potencial mercantil voltando-se à exploração do EaD como nicho de mercado. Os dados de 2012 evidenciam que $83,69 \%$ das matrículas estão no ensino privado e 16,31\%, no ensino público (INEP, 2013; CRUZ, 2015).

Particularmente, a maior expansão do EaD representa a ampliação de um instrumento de "pseudodemocratização" do acesso ao ensino superior, pois aumentou-se o número de vagas, mas com maior atenção ao interesse em atingir metas governamentais do que propriamente ampliar uma formação crítica. Desse modo, a virtualização do processo de ensino e aprendizagem promove um quadro de configurações às dinâmicas formativas, dimensionando uma "nova" lógica aos processos pedagógicos, os quais tendem a aprofundar o caráter residual, pragmático e tecnicista na 


\section{ApVistg all paUtg}

\} CRÍTICA À FORMAÇÃO PROFISSIONAL - SILVA, A. I. C. \}

DOI: 10.12957/REP.2016.25389

educação. Além disso, atua como indutor das configurações do papel do trabalho docente, haja vista a afirmação da figura de tutores em detrimento da figura do professor.

\section{O processo de expansão dos cursos de Serviço Social no Brasil e no Ceará}

O Serviço Social brasileiro, historicamente, atravessou um conjunto de mudanças quanto às dimensões teórico-metodológicas, técnicas, ideopolíticas e pedagógicas. Ao referirmo-nos, especificamente, ao quadro de alterações formuladas no Movimento de Reconceituação (entre os anos de 1960 e 1980), no espectro de disputas entre as correntes que se reproduziram (Modernização Conservadora, Reatualização do Conservadorismo e Intenção de Ruptura), a Intenção de Ruptura corresponde a um caminho de reflexão crítica à postura conservadora da profissão. Além disso, também critica a percepção de que o trabalho profissional estaria vinculado ao reconhecimento e à viabilização de direitos sociais à classe trabalhadora. O amadurecimento da criticidade da profissão foi fundamental para a construção coletiva do Projeto Ético-Político, entendido por Netto (2006) como instrumento que dimensiona a direção social e ético-política profissional.

A historicidade da profissão tem como patrimônio político-pedagógico, situado como referência fulcral no processo de formação profissional, o documento das Diretrizes Curriculares da Associação Brasileira de Ensino e Pesquisa em Serviço Social (Abepss), de 1996. Para lamamoto (2014), este documento corresponde a um acúmulo de forças no interior da profissão, tendo como importante antecedente histórico-político o currículo mínimo aprovado em 1982, expressão de um processo de transição, marcado pela resistência acadêmica e política à Ditadura Militar no Brasil.

As Diretrizes Curriculares da Abepss, de 1996, foram construídas como fruto de um intenso debate realizado entre a Associação Brasileira de Ensino em Serviço Social (Abess), atual Abepss, as unidades de ensino, os professores e estudantes dos cursos de Serviço Social espalhados pelo Brasil, por meio de oficinas locais, regionais e nacionais. Essas diretrizes são implementadas tendo em vista o reconhecimento do antagonismo de interesses de classes que fundamentam projetos em disputa, evidenciando uma clara orientação ético-política, pautada na dimensão da emancipação política e humana e no comprometimento com as lutas da classe subalternizada, em busca de novas formas de sociabilidade. O documento particulariza o Serviço Social no conjunto das relações de produção e reprodução da vida social, constituindo-se numa profissão de caráter investigativo e interventivo, com atuação nas expressões da questão social. Ainda, dimensionam os princípios de descentralização, pluralismo, bem como a indissociabilidade entre ensino, pesquisa e extensão (ABESS/CEDEPSS, 1997). 


\section{heVistg enl pautg}

\} CRÍTICA À FORMAÇÃO PROFISSIONAL - SILVA, A. I. C. \}

DOI: 10.12957/REP.2016.25389

Nas Diretrizes Curriculares da Abepss, o pressuposto fundamental é de que a formação profissional expresse uma concepção de ensino e aprendizagem calcada na dinâmica da vida social, estabelecendo parâmetros para inserção profissional crítica na realidade socioinstitucional. A proposta de formação parte da reafirmação do trabalho como atividade central na constituição do ser social, bem como na apreensão de que as mudanças verificadas nos padrões de acumulação e regulação social exigem um redimensionamento das formas de pensar/agir dos profissionais diante das novas demandas, possibilidades e respostas dadas.

A partir da análise das Diretrizes Curriculares da Abepss, visualizamos que existem princípios claramente explicitados, compromissados com a qualidade da formação profissional. Dentre eles, destacamos:

[...] 2. Rigoroso trato teórico, histórico e metodológico da realidade social e do Serviço Social, que possibilite a compreensão dos problemas e desafios com os quais o profissional se defronta no universo da produção e reprodução da vida social; 3. Adoção de uma teoria social crítica que possibilite a apreensão da totalidade social em suas dimensões de universalidade, particularidade e singularidade; 4. Estabelecimento das dimensões investigativa e interventiva como princípios formativos e condição central da formação profissional, e da relação teoria e realidade; 8 . Indissociabilidade nas dimensões de ensino, pesquisa e extensão; 11. Ética como princípio formativo perpassando a formação curricular. (ABESS/CEDEPSS, 1997, p.6).

Destarte, conforme lamamoto (2014), a proposta de currículo mínimo apresentada pela categoria sofreu com os rebatimentos da contrarreforma da educação superior, através da substituição por Diretrizes Curriculares mais flexíveis, exigindo a redefinição do perfil do bacharel em Serviço Social, a substituição de ementas das disciplinas por tópicos de estudos com caráter não obrigatório e a definição de competências e habilidades técnico-operativas. Em meio às exigências legais, foi criada uma Comissão de Especialistas em Serviço Social, que revisou o documento, adequando-o à proposta de formação orientada pelo Projeto Ético-Político da profissão.

Se, por um lado, visualizamos as Diretrizes Curriculares da Abepss (1996) e da Comissão de Especialistas (1999) assumindo um compromisso em ensejar, ao longo do processo de formação acadêmica, o nosso Projeto Ético-Político, as Diretrizes Curriculares propostas pelo MEC, em 2002, reiteram a razão formal-abstrata. Esta, na perspectiva de Guerra (2011), representa uma forma de pensar alijada de um compromisso de classe, vinculada à ideologia burguesa. Portanto, estão distantes do direcionamento a formação profissional acumulada como reserva de forças da profissão, fruto de resistências e embates com a ofensiva do capital sobre a política de ensino superior. 


\section{ApVistg all paUtg}

\} CRÍTICA À FORMAÇÃO PROFISSIONAL - SILVA, A. I. C. \}

DOI: 10.12957/REP.2016.25389

Passados 20 anos da elaboração das Diretrizes Curriculares da Abepss, é importante refletir sobre as particularidades do processo formativo na contemporaneidade, destacando os desafios postos à formação no cenário de expansão dos cursos de Serviço Social através da modalidade de ensino a distância.

Dados divulgados pelo Inep, em 2013, explicitam a existência de 405 cursos de Serviço Social no Brasil, sendo 18,3\% no ensino público e $81,7 \%$ ofertados no ensino privado. Quanto às matrículas, do total de $173.758,16,5 \%$ estavam na esfera pública e $83,5 \%$ na iniciativa privada. A expansão dos cursos de Serviço Social não ocorreu somente através das IES privadas presenciais e do ensino público, pois o $\mathrm{EaD}$ situou-se como uma modalidade de ensino com exponencial aumento das matrículas no referido curso. De 2006 a 2014, a base de dados do Sistema E-mec, do Inep, apresentou a existência de 27 instituições de ensino superior EaD com oferta de cursos de Serviço Social. Somente uma IES - a Unitins - é pública (estadual), sendo as demais de natureza privada, demonstrando o interesse empresarial por esse tipo de curso (INEP, 2015).

Pela análise do ritmo de abertura de novos cursos de Serviço Social na modalidade EaD, verificamos que, por mais que o número de cursos seja menor do que os ofertados pelo ensino presencial, em termos de matrículas há predominância do EaD. Pereira (2014) mostra que, em $2012^{2}$, havia 97.428 matriculados no EaD e 75.551 no ensino presencial. Entendemos que as IES com oferta EaD expandem massivamente a quantidade de vagas, motivo concernente à própria natureza destes cursos, cujos estudantes encontram-se dispersos em polos situados pelas cidades brasileiras.

A tabela abaixo compara a relação entre a expansão de cursos de Serviço Social EaD e presencial (público e privado). Torna evidente o crescimento do número de IES a distância que têm investido no curso de Serviço Social.

\section{Tabela 2}

\section{Cursos de Serviço Social no Brasil de acordo com a modalidade de ensino (2006-2014)}

$\begin{array}{lllllllll}\text { Ano } & 2006 & 2007 & 2008 & 2009 & 2010 & 2011 & 2012 & 2014 \\ \text { EaD } & 01 & 05 & 10 & 12 & 15 & 14 & 18 & 27 \\ \text { Presencial } & 224 & 262 & 287 & 307 & 333 & 358 & 376 & 378\end{array}$

Fonte: Elaboração do autor com base em Inep (2015) e Pereira (2014)

\footnotetext{
${ }^{2}$ Os dados de 2013 não explicitam as matrículas de acordo com a modalidade, se presencial ou EaD, por isso utilizamos dados de 2012.
} 
No Ceará, a origem dos cursos de Serviço Social remonta à Escola de Serviço Social vinculada ao Instituto Social de Fortaleza, administrado pela Congregação da Sociedade das Filhas do Coração de Maria, tendo como data oficial de sua criação o dia 25 de março de 1950. Ainda em seus primeiros anos, o curso esteve agregado à Universidade Federal do Ceará (UFC) e, no ano de 1975, foi incorporado à Universidade Estadual do Ceará (UECE) (CUNHA, 2012). Até o ano de 2005, somente a UECE era responsável pela oferta de cursos de Serviço Social no referido estado; assim, o movimento de expansão do ensino superior brasileiro, sobretudo mercantilizado, potencializou o rápido surgimento de novos cursos de Serviço Social.

Particularmente nos últimos dez anos, ocorreu uma ampliação dos cursos presenciais e EaD, acompanhando uma tendência nacional. Em 2015, dos 24 cursos de Serviço Social no Ceará, 8,0\% (2) estavam na esfera pública e $92 \%$ (22) em IES privadas. De modo geral, 17 são presenciais e 7 na modalidade de ensino a distância ${ }^{3} .17$ cursos são presenciais, dos quais 15 estão em IES privadas e 2 pertencem à esfera pública (uma instituição estadual - a UECE, em Fortaleza - e outra federal - o Instituto Federal de Educação, Ciência e Tecnologia, situado na cidade de Iguatu) (INEP, 2015).

O processo de ampliação da interiorização dos cursos de Serviço Social tem se apresentado como uma tendência atual. Pelos dados coletados, tendo como parâmetro as particularidades do Ceará, percebemos que este fenômeno está ocorrendo por intermédio dos cursos da modalidade EaD. Ainda que representem somente 7 IES, num universo de 24 que oferecem o curso de Serviço Social no Ceará, o EaD é ofertado em 38 polos situados em 20 cidades. Como visto, a interiorização da formação profissional em Serviço Social tem sido ampliada pelo EaD, na medida em que grupos empresariais visualizam a perspectiva de lucratividade na oferta do curso. Processo demarcado pela existência de valores mais acessíveis, conforme averiguamos na pesquisa exploratória, em relação aos cursos de Serviço Social presenciais (cujas mensalidades da formação no $\mathrm{EaD}^{4}$ chegam a custar entre $R \$ 200,00$ e $R \$ 300,00)$, e com presença de polos por muitas cidades interioranas. Dessa maneira, leva-se para os moradores dos municípios a ideologia da educação como salvaguarda da ascensão social, dimensionando uma inversão na educação como direito social e tratando-a como um serviço a ser vendido de "modo fácil", no caso do EaD.

Entre os anos de 2010 e 2014, cerca de 3.767 registros profissionais foram realizados. Destes, 2.197 são ex-estudantes de IES do Ceará. Do ensino privado presencial ocorreram 35,3\% das inscrições; da UECE, 13,3\%, e do EaD os números revelaram 51,3\% (1.127 de inscritos). Os dados nos

\footnotetext{
${ }^{3}$ Os cursos EaD estão localizados nas seguintes IES: Universidade do Norte do Paraná (Unopar), Universidade Anhanguera (Uniderp), Universidade Luterana do Brasil (Ulbra), Universidade Paulista (Unip), Universidade Estácio de Sá (Unesa), Centro Universitário UniSEB e Universidade do Sul de Santa Catarina (Unisul).

${ }^{4}$ Pesquisa realizada no site do Inep (2015).
} 


\section{ApVistg all paUtg}

\} CRÍTICA À FORMAÇÃO PROFISSIONAL - SILVA, A. I. C. \}

DOI: 10.12957/REP.2016.25389

mostram que, atualmente, mais de $50 \%$ dos assistentes sociais formados por IES com sede ou polos no Ceará são oriundos do ensino a distância, o que, por sua vez, acarreta em mudanças no perfil e na perspectiva de formação profissional (CRESS/CE, 2014).

Diante das questões apontadas, destacamos as considerações de lamamoto (2012), ao afirmar que o desmensurado crescimento do quadro profissional nas últimas décadas, sobretudo a expansão acelerada do ensino superior privado (em particular, o ensino a distância), vem desencadeando implicações na qualidade acadêmica da formação e no aligeiramento do trato da teoria, cuja ênfase recai mais no treinamento e menos na descoberta científica. A massificação e a perda da qualidade facilitam a submissão dos profissionais às demandas e "normas do mercado", tendentes a um processo de despolitização.

A autora acima citada declara que dificilmente a oferta de trabalho poderá acompanhar, no mesmo ritmo, o crescimento do contingente de assistentes sociais, uma vez que tal processo vem sendo acompanhado do crescimento do desemprego e da precarização das condições de trabalho, bem como do aumento da insegurança no emprego e da elevação dos níveis de concorrência no mercado de trabalho (IAMAMOTO, 2014).

\section{A proposta de formação profissional em Serviço Social EaD da Unopar: análise das características da metodologia de ensino e do formato da organização curricular}

A Universidade do Norte do Paraná (Unopar) é uma IES privada, com fins lucrativos, que está há mais de quarenta anos no mercado educacional brasileiro ${ }^{5}$. Atualmente, a instituição é reconhecida como uma das universidades com maior oferta de vagas no ensino a distância no Brasil, atuando na mercantilização de cursos de graduação e pós-graduação em 450 municípios brasileiros (UNOPAR, 2015). Em 2011, a Unopar foi adquirida pelo grupo Kroton Educacional, uma companhia que investe capital na área da educação, por intermédio do aporte financeiro do fundo de investimento Advent International. O curso de Serviço Social EaD da Unopar funciona desde 12 de fevereiro de 2007, com carga-horária de 3.020 horas, distribuída em oito semestres. É líder na oferta de vagas anuais para o curso de Serviço Social no Brasil, com 21.150 vagas autorizadas. Estudar no curso de Serviço Social da Unopar custa mensalmente $R \$ 237,00$, com matrícula semestral de R\$59,00 (KROTON EDUCACIONAL, 2015).

Com o escopo de problematizar a perspectiva de formação profissional em Serviço Social, na modalidade de ensino a distância, analisamos

\footnotetext{
${ }^{5}$ Fundada em 1972, a Unopar é fruto da consolidação do investimento empresarial de um grupo de professores de Londrina, no Paraná (UNOPAR, 2015).
} 
o conteúdo do documento intitulado Guia de percurso do curso de Serviço Social, da Unopar. Este guia corresponde à proposta político-pedagógica de formação, especificando as características da metodologia de ensino e do formato da organização curricular. De acordo com o referido documento, o objetivo do curso de Serviço Social na modalidade EaD é:

[...] formar profissionais com capacidade teórica, técnica, política e ética inserida e comprometida com o projeto societário emancipatório. O curso objetiva formar profissionais com capacidade de examinar, analisar e interpretar a sociedade capitalista - base estrutural da produção da 'questão social' - para intervenção profissional comprometida com os valores de liberdade e justiça social. (UNOPAR, 2013, p. 7).

Quanto à direção do processo formativo, ele afirma que o profissional a ser formado estaria em consonância com as Diretrizes Curriculares para a formação profissional em Serviço Social, afirmando que a formação profissional deve viabilizar a "[...] capacitação teórico-metodológica e éticopolítica, como requisito fundamental para a realização de atividades técnicooperativas, com vistas à apreensão crítica dos processos sociais numa perspectiva de totalidade." (UNOPAR, 2013, p. 8). Destarte, verificamos que o documento não sinaliza se a referência do processo formativo toma como parâmetro as Diretrizes Curriculares da Abepss, de 1996, ou do MEC, de 2002.

Entendemos que, ainda que fosse feita menção direta às Diretrizes Curriculares da Abepss, de 1996, seria inviável a articulação entre o curso EaD e a proposta da referida associação, pois a existência em si de um curso EaD já é algo contestável na categoria, dado que os cursos nesta modalidade não estão em alinhamento com o pressuposto de uma formação calcada na dimensão efetivamente presencial, pública, parametrada no tripé ensino, pesquisa e extensão, e com ricas vivências acadêmicas. Estas permitiram ao estudante estabelecer relações de sociabilidade e possíveis processos de articulação estudantil/política dos mesmos.

Destacamos que a polêmica campanha impulsionada pelo Conselho Federal de Serviço Social (CFESS), em parceria com a Abepss, pelos Conselhos Regionais de Serviço Social (Cress), pela Executiva Nacional de Estudantes de Serviço Social (Enesso) e pelo Sindicato Nacional dos Docentes das Instituições de Ensino Superior (Andes-SN), intitulada Educação Não é Fast Food: diga não para a graduação a distância em Serviço Social, teve como objetivo denunciar a situação de precarização, mercantilização e discriminação da educação superior no Brasil, de modo a particularizar a realidade da expansão desenfreada dos cursos de Serviço Social, via EaD. A campanha foi veiculada em 2011 e, a partir de agosto do ano em questão, por ordem judicial, foi proibida de continuar sendo divulgada (CFESS, 2011).

Visualizamos uma explícita contradição na proposta político-pedagógica da Unopar, a qual aponta que o curso de Serviço Social no EaD 


\section{ApVistg all paUtg}

\} CRÍTICA À FORMAÇÃO PROFISSIONAL - SILVA, A. I. C. \}

DOI: 10.12957/REP.2016.25389

teria como perspectiva a construção de uma sociedade emancipada. Contudo, a metodologia de ensino e o formato pedagógico adotado não condizem com a direção crítica para o debate da superação do capitalismo; pelo contrário, tendem a reforçá-lo ideologicamente, na medida em que este modelo pedagógico amplia as possibilidades de adequação dos sujeitos sociais à ordem burguesa estabelecida.

O documento analisado explicita um conjunto de informações a respeito de como funciona o curso de Serviço Social no EaD, que se apresenta como semipresencial. Preliminarmente, destaca que o curso funciona com atividades assincrônicas e sincrônicas, ou seja, é realizado por intermédio de aulas não presenciais e momentos presenciais (que acontecem uma vez por semana).

A metodologia de ensino baseia-se na utilização de recursos midiáticos, os quais compreendem: teleaulas via satélite, web aulas, ambiente virtual de aprendizagem, biblioteca digital, laboratório virtual, material impresso e aulas presenciais uma vez por semana para realização de atividades afins (trabalhos em grupos, provas, contato com tutor). As aulas presenciais são momentos em que os estudantes têm contato direto com o tutor das disciplinas transmitidas via satélite; há, ainda, a possibilidade de comunicação com os professores em tempo real através de um chat. O estudante deve ter no mínimo 50\% de presença nas atividades presenciais para ser aprovado nas disciplinas (UNOPAR, 2013).

Na sociedade capitalista, a formação dos trabalhadores foi capturada pelas necessidades de legitimação do capital, através das medidas de utilização da educação como instrumento ideológico de reforço ao imperativo da dominação de classe. Emergem, portanto, perspectivas pedagógicas direcionadas à formação de um trabalhador funcional e adaptado às determinações do mundo do trabalho. Deste modo, destacamos que a metodologia de ensino em análise mantém estreita relação com uma perspectiva pedagógica tecnicista. Esta, conforme Saviani (2011), diz respeito à reordenação do processo educativo, tornando-o objetivo e operacional. A pretensão é objetivar um trabalho pedagógico de maneira parcelada, fragmentada, pasteurizada, sem que haja análise da totalidade do fenômeno educativo.

A pedagogia tecnicista buscou planejar a educação de modo a cultivar uma organização racional voltada para operacionalização de determinadas propostas de ensino e mecanização do processo didático-pedagógico, promovendo a proliferação de propostas pedagógicas com foco no "microensino", no "tele-ensino", na instrução programada, nas "máquinas de ensinar" (SAVIANI, 2011). O caráter virtual do processo educativo é uma das expressões da nova racionalidade estabelecida na relação ensino/ aprendizagem, cujo tecnicismo dimensiona a sustentação pedagógica.

A concepção pedagógica tecnicista apoia-se na ideia de formação por competências; nesta acepção, o objetivo é dotar os indivíduos de com- 


\section{heVistg enl pautg}

\} CRÍTICA À FORMAÇÃO PROFISSIONAL - SILVA, A. I. C. \}

DOI: 10.12957/REP.2016.25389

portamentos flexíveis que lhes ajustem às requisições contemporâneas do capitalismo, ou seja, para que atinjam os objetivos de mercado na elaboração da figura de um trabalhador acrítico, polivalente, que aceite as condições de trabalho impostas, com trabalho desregulado ou terceirizado e direitos sociais cerceados. Traduz, portanto, a relação imbricada entre trabalho e educação. Afinal, assim como nas empresas capitalistas, as instituições educativas passaram a ter um ensino centrado na eficiência, racionalidade e produtividade. Não à toa, a diversificação dos modelos de ensino na educação superior vem respaldando-se diante de interesses de cariz mercadológico (SAVIANI, 2011).

Destacamos que, no decorrer da proposta político-pedagógica e nas características da metodologia de ensino adotada pela IES em análise, há uma culpabilização isolada do estudante nesta modalidade. Vejamos este trecho em que o documento analisado declara que: "Para sua organização de tempo e prazos a serem cumpridos para a entrega das atividades, é necessário que você aluno, tenha disciplina e administre seu tempo e também tenha responsabilidade no cumprimento das atividades propostas" (UNOPAR, 2013, p. 8). E continua:

O seu papel nesse sistema é, sem dúvida, o mais importante, pois você é o grande responsável pela aprendizagem. A principal meta é aprender, ou seja, empenhar-se em compreender, pesquisar, aplicar e construir conhecimento. Um aluno que opta por estudar a distância exercita sua autonomia, administrando seu tempo para a realização das atividades [...] O aluno tem a oportunidade de explorar seus pontos fortes, suas limitações [...]. Essa forma de contrato didático é o alicerce que constitui comunidades virtuais de aprendizagem dinâmicas e efetivas. (UNOPAR, 2013, p. 11).

A virtualização do fenômeno educativo tende a tornar a formação profissional um ato solitário, comprometendo o despertar crítico sobre o que de fato vem a ser a modalidade $\mathrm{EaD}$ e os interesses subjacentes à sua lógica de expansão. O estudante está diante de uma relação em que se opera o desenvolvimento pedagógico mediado por máquinas, conferindoIhe a forma e o conteúdo do conhecimento socializado; este, por sua vez, tende a ser reduzido à informação, na medida em que o processo pedagógico segue um ritual aligeirado, fragmentado e residual quanto aos mecanismos de apreensão dos conteúdos.

A "venda" dos cursos no formato EaD propala princípios de flexibilidade temporal, em que o estudante supostamente poderá administrar seu tempo como quiser. Tempo é a palavra mais usada para explicitar o discurso de que o estudante do EaD poderá "estudar" sem abrir mão de suas atividades cotidianas. Claro que qualquer estudante, seja este também oriundo do ensino presencial, necessita saber administrar bem seu tempo de estudo. No entanto, a perspectiva de formação em modelo de "autoestudo" com- 


\section{ApVistg all paUtg}

\} CRÍTICA À FORMAÇÃO PROFISSIONAL - SILVA, A. I. C. \}

DOI: 10.12957/REP.2016.25389

promete a dinâmica de organização acadêmica do estudante. Além disso, a ausência de articulação presencial com a experiência docente não permite um maior acompanhamento do amadurecimento teórico-metodológico do discente.

Em um ambiente virtual chamado "Colaborar", o formando tem acesso a um conjunto de atividades propostas e obrigatórias para o curso, chamado de "Portfólio". As atividades servem para elaboração de produções textuais individuais e coletivas, relacionadas ao conteúdo trabalhado no material didático em formato de apostilas, em que constam textos explicativos e exercícios em oito módulos, divididos em matérias ou componentes curriculares. São, portanto, um total de 42 disciplinas ministradas ao longo de oito semestres (3.020 horas de carga-horária total). Destaca-se também que o estudante deve participar de um fórum on-line de discussão para cada disciplina: este seria o contato mais interativo e imediato dos formandos entre si (UNOPAR, 2013).

No que diz respeito à dimensão organizacional do currículo do curso de Serviço Social da Unopar, abaixo realizaremos uma síntese da matriz curricular. Além disso, destacaremos o ementário de algumas disciplinas, no sentido de explicitar aspectos problemáticos do processo de formação profissional.

Cabe explicitar que, ao focar nas estratégias metodológicas da relação entre ensino e aprendizagem (discutidas acima) e na matriz curricular, destacamos o conteúdo do ementário de apenas algumas disciplinas, dadas as limitações de um artigo. No entanto, mostramos aos leitores o formato da organização curricular de todos os semestres letivos do curso de Serviço Social em análise.

Verificamos que o referido curso é desenvolvido em oito semestres letivos, com distribuição de cinco a seis disciplinas por semestre, em que cada um é caracterizado por uma temática pedagógica relativa à área do Serviço Social. O primeiro semestre, composto por seis disciplinas, é intitulado Fundamentos teórico-metodológicos das relações sociais, ofertando as seguintes disciplinas: Educação a Distância; Metodologia Científica; Antropologia; Formação Social, Histórica e Política do Brasil; Acumulação Capitalista e Desigualdade Social; e Seminário da Prática I. No semestre em questão, observamos que a IES propõe como uma das disciplinas Educação a Distância, com estudo introdutório acerca da organização do sistema de $\mathrm{EaD}$, os elementos da comunicação e informação contemporânea, e a relação dos sujeitos da prática pedagógica com o EaD (UNOPAR, 2013). Em nossa análise, percebemos que o ementário almeja afinar o estudante ao modelo pedagógico proposto, adequando "mentes" e "corações" à virtualização do processo de ensino e aprendizagem.

O segundo semestre, intitulado Fundamentos instrumentais, é composto pelas seguintes disciplinas: Fundamentos Históricos, Teóricos e Metodológicos do Serviço Social I; Filosofia; Sociologia; Ciência Política; 
Seminário de Prática II. Destacamos, aqui, as disciplinas de Filosofia e Sociologia, cujo ementário, para além da análise das correntes filosóficas e sociológicas, esboça: estudos sobre Avanços Tecnológicos, Inclusão e Exclusão Digital, no caso da Filosofia; já em Sociologia, estudos acerca da Sociedade do Conhecimento e Informação (UNOPAR, 2013, p. 17). Estes conteúdos atestam a vinculação da proposta de formação em Serviço Social EaD com as concepções contemporâneas de Sociedade em rede, Sociedade da Informação e Sociedade do Conhecimento. Os ideólogos defensores dessas ideias descartam a centralidade do trabalho na constituição do ser social e afinam um discurso de "revolução da informação".

O terceiro semestre, intitulado Fundamentos teórico-metodológicos e a questão social, apresenta cinco disciplinas: Fundamentos Históricos, Teóricos e Metodológicos do Serviço Social II; Economia Política; Política Social; Estatística e Indicadores Sociais; e Seminário de Prática III. Já no quarto semestre, intitulado Fundamentos do trabalho profissional, são ministradas estas disciplinas: Fundamentos Históricos, Teóricos e Metodológicos do Serviço Social III; Fundamentos das Políticas Sociais; Políticas Sociais, Administração e Planejamento em Serviço Social; Ética Profissional em Serviço Social; e Seminários da Prática IV.

Nos semestres elencados, visualizamos que, do ponto de vista da forma, a ementa das disciplinas corresponde ao que consta nas Diretrizes Curriculares da Abepss; no entanto, é preciso um estudo do material didático para identificar se estas disciplinas têm uma ementa que se restringe ao plano do formalismo no conteúdo, ao tentar utilizar as mesmas palavras apresentadas pela Abepss.

O quinto semestre, sob título-tema Trabalho profissional: dimensões e aplicabilidade técnico-operativa, elenca as seguintes disciplinas: Estágio em Serviço Social I; Pesquisa Social e Oficina de Formação; Políticas Setoriais e Políticas Setoriais Contemporâneas; Instrumentalidade em Serviço Social; Movimentos Sociais; e Seminários da Prática V. No quinto semestre, destacamos um deslocamento de conteúdo que deveria compor o núcleo de Fundamentos Históricos, Teóricos e Metodológicos do Serviço Social, mas que se apresenta na disciplina Políticas Setoriais e Políticas Setoriais Contemporâneas, conforme a ementa desta última: "A elaboração de um novo significado social do Serviço Social de redemocratização da sociedade brasileira. O pensamento crítico marxista no arcabouço teórico-metodológico do Serviço Social contemporâneo. O contexto neoliberal na década de 1990 e seus reflexos na profissão" (UNOPAR, 2013, p. 19). A ementa explicita um núcleo temático que não mantém coerência com a própria nomenclatura da disciplina.

Outro aspecto a ser problematizado no semestre em questão corresponde à disciplina Instrumentalidade em Serviço Social, cuja ementa privilegia a perspectiva de um tratamento meramente técnico ao ensino da instrumentalidade, não explicitando a dimensão ontológica e a articulação 


\section{ApVistg all paUtg}

\} CRÍTICA À FORMAÇÃO PROFISSIONAL - SILVA, A. I. C. \}

DOI: 10.12957/REP.2016.25389

vital entre as dimensões teórico-metodológicas, ético-políticas e técnicooperacionais, como se verifica: "A categoria instrumentalidade. Conhecimento e aplicação de instrumental técnico-operacional e as novas tecnologias utilizadas pelo Serviço Social. Documentos técnicos da prática profissional. Ação interdisciplinar" (UNOPAR, 2013, p. 19).

No sexto semestre, intitulado $O$ trabalho profissional: a intervenção profissional, oferece as seguintes disciplinas: Estágio em Serviço Social II; Serviço Social na Área da Saúde; Previdência e Assistência Social; Serviço Social e Processo de Trabalho; Direito e Legislação; e Seminário de Prática VI. É neste período que se verifica uma única disciplina voltada ao estudo das principais políticas setoriais em que atua o Serviço Social: saúde, assistência social e previdência social. Referimo-nos à disciplina Serviço Social na Área da Saúde, Previdência Social e Assistência Social, que, com apenas 120 horas/aulas, evidencia o "casamento" do EaD com as prerrogativas da aceleração do processo de formação profissional; afinal, como aprofundar o debate crítico acerca das políticas sociais setoriais em uma disciplina formatada em bloco sintético da seguridade social? Que concepção de proteção social vem sendo estudada nos cursos EaD?

No sétimo semestre, sob o título $O$ trabalho profissional: gestão, pesquisa e comunicação, os estudantes têm acesso a estas disciplinas: Estágio em Serviço Social III; Projeto de Trabalho de Conclusão de Curso; Gestão e Análise de Políticas Sociais; Comunicação na Prática Profissional; Seminários da Prática VII; e Tópicos Especiais I. Quanto a este semestre, destacamos, a partir da análise do ementário, que a introdução da disciplina Comunicação na Prática Profissional tende a dimensionar um ensino da prática em que se evidencia um modelo formativo marcado pelas requisições de um trabalhador muito mais adaptado ao desenvolvimento das tecnologias e técnicas de comunicação para instrumentalização da prática profissional. Negligenciando, obviamente, o amadurecimento intelectual que permita o fomento a críticas acerca da concepção de comunicação e ensino a distância.

É no sétimo e oitavo semestres que os estudantes passam a ter acesso a discussões sobre o projeto de Trabalho de Conclusão de Curso (TCC). Conforme verificamos no documento em análise, na Unopar, quando requisitado, o TCC é utilizando como instrumento de avaliação final do curso. O documento estudado afirma que o TCC é avaliado por um tutor eletrônico sob a supervisão de um professor orientador. No entanto, não evidencia como se dá o processo de orientação, se acontece através de acompanhamento direto e presencial de um profissional, ou se por intermédio de um conjunto de atividades realizadas também a distância ${ }^{6}$.

\footnotetext{
${ }^{6}$ As Diretrizes Curriculares da Abepss (1996) apontam que o TCC trata-se de uma exigência curricular para a obtenção do diploma do curso de graduação em Serviço Social. É o momento de síntese e expressão da totalidade do processo formativo, por meio do qual o estudante sistematiza o conhecimento resultante de um processo investigativo, originário de um questionamento teórico.
} 


\section{heVistg enl pautg}

\} CRÍTICA À FORMAÇÃO PROFISSIONAL - SILVA, A. I. C. \}

DOI: 10.12957/REP.2016.25389

Por fim, no oitavo semestre, com o título O Trabalho Profissional: Intervenção Analítica, existem as seguintes disciplinas: Trabalho de Conclusão de Curso; Terceiro Setor, Meio Ambiente e Sustentabilidade; Seminário da Prática VIII; Tópicos Especiais II; e uma optativa (Libras ou Educação Inclusiva). A ementa da disciplina Terceiro Setor, Meio Ambiente e Sustentabilidade mostra que o conteúdo a ser estudado está imerso em um quadro conceitual que foge ao projeto hegemônico de Serviço Social no Brasil, ao manejar os conceitos de sociedade de risco, agenda sustentável e responsabilidade social.

É fundamental considerar que as Diretrizes Curriculares da Abepss explicitam como parte da organização curricular a existência de núcleos de fundamentação, que consistem na perspectiva de articulação de um conjunto de conhecimentos indissociáveis ao processo de formação profissional, com vistas à constituição de conteúdos formativos densos, orgânicos e respaldados do ponto de vista teórico-metodológico, ético-político, cultural e pedagógico. Tais núcleos dividem-se em: núcleos de fundamentos da vida social, núcleos de fundamentos da formação sócio-histórica brasileira e núcleo de fundamentos do trabalho profissional.

O curso de Serviço Social EaD da IES estudada evidencia que o formato da organização curricular privilegia eixos temáticos fincados em um conjunto de ementas que negligencia a dimensão teórico-metodológica consistentemente crítica e com adensamento na tradição marxista. Desse modo, dá maior ênfase aos estudos que respaldam o fazer profissional, dissociando a relação teórico-prática, na condição de uma unidade essencial ao processo de formação profissional. Os eixos temáticos de cada semestre, que dão origem à organização das disciplinas, não dialogam, do ponto de vista da consistência político-pedagógica, com os núcleos de fundamentação propostos pelas Diretrizes Curriculares da Abepss.

O que se desenha na lógica curricular EaD da Unopar são as proposições que tendem a tecnificar a prática profissional ao dar ênfase em excesso às ideias de fundamentos instrumentais, dimensões e aplicabilidades técnico-operativas e intervenção analítica. Não queremos, aqui, reproduzir uma interpretação teoricista dos dados ao mostrar o dimensionamento técnico-operativo; não negligenciamos que este cumpre papel fundamental no projeto profissional crítico do Serviço Social. Destarte, percebemos que a metodologia de ensino e a organização do curso no formato $\mathrm{EaD}$ tende a obscurecer a necessidade de adensamento intelectual crítico no processo formativo, endereçando-se para um caminho em que tecnicismo, pragmatismo e análise formal-abstrata da realidade operam político-ideologicamente como esteio à racionalidade hegemônica da produção e reprodução do capital.

A formação em Serviço Social, conforme as Diretrizes Curriculares da Abepss, propõe um processo formativo crítico, com reconhecimento da importância da dimensão investigativa, aprofundamento da teoria crítica e 


\section{ApVistg all paUtg}

\} CRÍTICA À FORMAÇÃO PROFISSIONAL - SILVA, A. I. C.

DOI: 10.12957/REP.2016.25389

amadurecimento teórico-metodológico, ético-político e técnico-operativo; assim, a dinâmica formativa pautada em "apostilas", "módulos", conteúdo dado de modo sintético, fragmentado e aligeirado inviabilizam o fortalecimento pedagógico e ideopolítico crítico da formação profissional.

\section{Considerações finais}

Ao longo do texto, explicitamos que a formação profissional em Serviço Social tem sido atravessada por alterações de fundo, cuja dinâmica, por meio do EaD, mostra-se como mecanismo que apresenta um quadro de tensionamentos concernentes à formação e ao exercício profissional dos assistentes sociais.

Os dados acerca da expansão dos cursos na modalidade EaD no Ceará acompanham uma tendência nacional quanto à massificação do processo formativo. Neste aspecto, por mais que tenham se ampliado alguns espaços sócio-ocupacionais para atuação do Serviço Social, concordamos com lamamoto (2011) ao afirmar que dificilmente o imenso quantitativo de assistentes sociais em processo de formação será absorvido pelo mercado de trabalho, haja vista a existência real de desemprego na sociedade do capital.

O processo de formação profissional através do EaD está conjugado por um quadro de intensas fraturas no ensino de graduação. Como explicitamos, as características da metodologia de ensino e o formato da organização curricular da proposta político-pedagógica da instituição estudada mostram os aspectos que perpassam a forma de ensino/aprendizagem, cuja tônica da virtualização atua como instrumento que tende à formação residual, pragmática, tecnicista, acrítica e sob a racionalidade formal-abstrata. A "máquina" informacional torna-se instrumento pedagógico de mediação do processo de ensino e aprendizagem, desconsiderando a necessária relação social construída por mecanismos pedagógicos presenciais. $\mathrm{O}$ estudante tende a ser capturado pelo universo da atratividade esboçada na venda de um curso EaD, afinal, conforme verificamos na IES estudada, apresentam-se a ele vantagens de flexibilidade temporal, através do acesso às plataformas de ensino.

A metodologia evidencia a ausência de contato mais profundo entre professores e estudantes e estudantes entre si. Compreendendo a formação de um trabalhador contemporâneo conectado ao uso das TICs que, ao virtualizar o processo educativo, transforma o sentido sócio-histórico, crítico e reflexivo do conhecimento em informações imediatistas e mediadas pelas concepções de "sociedade em rede", "sociedade da informação" e "revolução informacional".

Com base no estudo do formato curricular e do ementário das disciplinas, apreendemos que seu desenho substancia-se em uma lógica 


\section{ReVistg ell pautg}

\} CRÍTICA À FORMAÇÃO PROFISSIONAL - SILVA, A. I. C. \}

DOI: 10.12957/REP.2016.25389

que não converge com a proposta político-pedagógica de formação da Abepss, consubstanciada nas Diretrizes Curriculares de 1996. Identificamos uma tendência à tecnificação da concepção de formação e exercício profissional, no sentido de que se expressa uma ênfase em aspectos relativos à "instrumentalização" do trabalho profissional, sem aprofundamento intelectual crítico, dimensionado pela relação indissociável entre os aspectos teórico-metodológicos, ético-políticos e técnico-operativos do projeto profissional crítico.

Destacamos que nossa análise, ao partir do que é apresentado no Guia de percurso do curso de Serviço Social, da Unopar (2013), reconhece que este documento apresenta limitações, de modo que precisamos aprofundar pesquisas com vistas à apropriação acerca da realidade cotidiana dos processos pedagógicos da formação no EaAD. Destarte, salientamos que, nos limites deste artigo, nossas reflexões fomentaram a busca por conhecer criticamente algumas características do processo formativo na referida modalidade.

Por fim, evidenciamos que os estudantes do ensino a distância são maioria quantitativa na profissão; no entanto, acreditar que o que está posto torna-se irreversível é não ter a capacidade de alargar os horizontes para a possibilidade de mudanças concretas na sociedade e na política educacional. Desse modo, a bandeira de luta da categoria deve continuar sendo a de posicionamento contrário à lógica da formação profissional no $\mathrm{EaD}$, entendendo o quadro de configurações que isso acarreta à profissão. Claro que a crítica refere-se ao fato de que a virtualização da formação profissional, com base no $\mathrm{EaD}$, não contempla a proposta político-pedagógica de formação profissional que a Abepss defende.

Destacamos que não desconsideramos a existência do processo de precarização do ensino público e privado presencial, haja vista que estes espaços também são atingidos pelas configurações da política de ensino superior no cenário neoliberal. Nossa luta deve continuar sendo por uma edcação pública, presencial, gratuita, laica, com qualidade e que atenda aos interesses da classe trabalhadora. 


\section{ApVistg all paUtg}

\} CRÍTICA À FORMAÇÃO PROFISSIONAL - SILVA, A. I. C. \}

DOI: 10.12957/REP.2016.25389

\section{Referências}

ABESS/CEDEPSS. Formação Profissional: trajetórias e desafios. Cadernos ABESS, no 07. 1997.

BANCO MUNDIAL. La enseñanza superior: las lecciones derivadas de la experiencia (el desarrollo en la práctica). Washington: Bird/Banco Mundial. 1994.

Boletim Cress/CE. Alteração do Perfil e Ampliação das Inscrições de Profissionais no CRESS/CE, 2014.

BRASIL. Lei de Diretrizes e Bases da Educação Nacional. Lei n. 9.394/96, de 20 de dezembro de 1996. 1996. Disponível em: <http://portal.mec. gov.br/seed/arquivos/pdf/tvescola/leis/lein9394.pdf.>. Acesso em: 8 jun. 2015. abr. 2015.

Inep. 2015. Disponível em: <http://emec.mec.gov.br/>. Acesso em:

Programa de Apoio a Planos de Reestruturação e Expansão das Universidades Federais (Reuni), 2013. Disponível em: <http://reuni.mec.gov. br/o-que-e-o-reuni>. Acesso em: 10 de agosto de 2014.

CASTELLS, M. A galáxia da internet: reflexões sobre a internet, os negócios e a sociedade. Rio de Janeiro: Zahar. 2003.

CFESS. Sobre a incompatibilidade entre graduação a distância e Serviço Social. 2011. Disponível em: <http://www.cfess.org.br/arquivos/01_sobrea incompatibilidade_2011.pdf.>. Acesso em: 10 ago. 2015.

CHESNAIS, F. Mundialização: o capital financeiro no comando. Outubro, v. 5. 2002. Disponível em: <www.revistaoutubro.com.br/edicoes/05/out5_ 02.pdf.>. Acesso em: 9 mai. 2015.

CISLAGHI, J. F. Financiamento do ensino superior no Brasil: novos e antigos mecanismos de privatização do fundo público. In: SALVADOR, E. et al. (Org.). Financeirização, fundo público e politica social. São Paulo: Cortez. 2012.

CRESS/CE. Conselho Regional de Serviço Social, 3aㅡ região. Relatório: dados sobre o número de inscritos 2010 a 2013. Ceará: Cress. 2014..

. Boletim. Alteração do perfil e ampliação das inscrições de profissionais no CRESS/CE. Ceará: Cress. 2014.

CRUZ, A. G. Educação superior a distância: paradoxos presentes na formação de professores. Tese (Doutorado - Programa de Pós-graduação em Educação - PPGE) Universidade Federal Fluminense, Niterói. 2015. Disponível em: <www.ppgeducacao. uff.br/.../82_6c29357c62625a23da 5d0f50303e7cee.pdf.>. Acesso em: 6 jun. 2015. 


\section{ReVistg ell pautg}

\} CRÍTICA À FORMAÇÃO PROFISSIONAL - SILVA, A. I. C. \}

DOI: $10.12957 /$ REP.2016.25389

CUNHA, A. Maria. Projeto de pesquisa. História dos 60 anos do curso de Serviço Social no Ceará: particularidades da formação profissional na UECE. Fortaleza, 2012.

DRUCKER, P. Sociedade pós-capitalista. São Paulo: Pioneira. 1993.

GUERRA, Y. A instrumentalidade do Serviço Social. São Paulo: Cortez. 2011.

HARVEY, D. Condição pós-moderna: uma pesquisa sobre as origens da mudança cultural. São Paulo: Loyola. 1993.

IAMAMOTO, M. V. Serviço Social em tempo de capital fetiche: capital financeiro, trabalho e questão social. São Paulo: Cortez. 2011.

. O Serviço Social na contemporaneidade: trabalho e formação profissional. São Paulo: Cortez. 2012.

A formação acadêmico-profissional no Serviço Social brasileiro. Serviço Social e Sociedade, São Paulo, n. 120, out./dez. 2014.

INEP. Resumo Técnico: senso da educação superior, 2013. Disponível em: <http://portal.inep.gov.br/web/censo-da-educacao-superior/resumostecnicos> . Acesso em: abr. 2015

. Sistema E-mec, 2015. Disponível em<http://emec.mec.gov.br/.>. Acesso em: abr. 2015.

KROTON EDUCACIONAL. Portal. [2015]. Disponível em: <http://www.kro ton.com.br>. Acesso em: 10 ago. 2015.

LIMA, K. Contra-reforma na educação superior: de FHC a Lula. São Paulo: Xamã. 2007.

A política de educação superior a distância nos anos de neoliberalismo. Perspectiva, Florianópolis, v. 29, n. 1, jan./jun. 2011. Disponível em: <https://periodicos.ufsc.br/index.php/perspectiva/article/view/ 2175795X.2011v29n1p19o>. Acesso em: 6 jun. 2015.

MARX, K. Contribuição à crítica da economia política. São Paulo: Expressão Popular. 2008.

MÉSZÁROS, I. Educação para além do capital. São Paulo: Boitempo. 2008.

NETTO, J. P. A construção do Projeto Ético-Político do Serviço Social. In: MOTA, A. E. et al. Serviço Social e Saúde: formação e trabalho profissional. São Paulo: Cortez. 2006.

PEREIRA, L. D. Análise comparativa entre expansão dos cursos de Serviço Social EaD e presenciais. Temporalis, Brasília, ano XIV, n. 27, jan./jun. 2014.

RODRIGUES, J. Os empresários e a educação superior. Campinas: Autores Associados. 2007. 


\section{heVista dII Pautg}

\} CRÍTICA À FORMAÇÃO PROFISSIONAL - SILVA, A. I. C. \}

DOI: 10.12957/REP.2016.25389

SAVIANI, D. História das ideias pedagógicas no Brasil. Campinas: Autores Associados. 2011.

UNOPAR. Universidade do Norte do Paraná. Guia de percurso do curso de Serviço Social. 2013. Disponível em: <http://www.unoparead.com.br/ documentos/guia-percurso/servico-social.pdf.>. Acesso em: 10 abr. 2015. . Portal. [2015]. Disponível em: <http://www.unoparead.com.br/>. Acesso em: 10 ago. 2015.

Recebido em 28 de abril de 2016.

Aprovado para publicação em 8 de julho de 2016.

DOI: 10.12957/rep.2016.25389

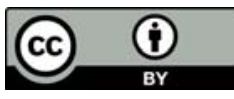

A Revista Em Pauta: Teoria Social e Realidade Contemporânea está licenciada com uma Licença Creative Commons Atribuição 4.0 Internacional. 